\title{
The early diagnosis of lung cancer
}

\author{
T. J. DEELEY \\ M.B., Ch.B., F.F.R., D.M.R.T.

\begin{abstract}
Director of The South Wales and Monmouthshire Radiotherapy Service
\end{abstract} \\ and Lecturer, Welsh National School of Medicine, Cardiff
}

\begin{abstract}
Summary
Earlier diagnosis of malignant disease in the lung may bring about improvements in the treatment. This article discusses the effects of early diagnosis on the prognosis. Cancer of the lung may be associated with other lung pathology, thus increasing the problems of diagnosis. Diagnosis depends on radiological examination, cytology of the sputum, radio-isotope lung scanning and mediastinoscopy: an account is given of how these may be used to diagnose the condition whilst it is still at an early stage and suitable for radical treatment.
\end{abstract}

'Alas regardless of their doom, The little victims play.

No sense have they of ills to come, Nor cares beyond today.'

THESE words, taken from a poem by Thomas Gray, aptly describe the insidious progress of carcinoma of the bronchus; by the time that symptoms develop the disease has often reached the stage when operation, if feasible, is seldom curative. Thompson (1967) in a series of 1070 patients admitted to hospital with a bronchogenic carcinoma, found that $50 \%$ were unsuitable for surgery on clinical grounds, $20 \%$ were inoperable at bronchoscopy and a further $10 \%$ were found to be inoperable at thoracotomy. Thus, in $80 \%$ of these patients all that can be offered is a small chance of a cure by radiotherapy-a 5-year survival of $6 \%$ in inoperable cases was reported by Deeley $\&$ Singh (1967)—or else the possible relief of distressing symptoms. Too often, 'it is too late, if only he had come earlier'; an earlier presentation may have meant that the disease was operable, or, even if locally extensive, it may not have been disseminated and there may have been the chance of radical radiotherapy treatment and possible cure.

A considerable part of a radiotherapist's time is spent, not in treating patients with a possibility of a permanent cure, but in palliating distressing symptoms (Morrison \& Deeley, 1960; Line \& Deeley, 1971), and in trying to salvage a few patients from those who already have metastatic disease in the brain (Deeley \& Rice Edwards, 1968) and at other sites where the tumour may be solitary (Deeley \& Line, 1969).

Control of cancer of the bronchus may be brought about in three ways-by prevention of the disease, by earlier diagnosis and by improved methods of treatment. Prevention demands abolition of smoking -which so far has proved impossible. Existing treatment methods are inadequate but perhaps, if the disease could be diagnosed at an earlier stage these results may be improved. The purpose of this paper is to review methods of bringing about an earlier diagnosis in established cases of carcinoma. In several fields work is in progress but future progress will depend upon closer co-operation between the family doctor, the chest physician, the radiologist, the cytologist and the patient himself.

The consideration of the diagnosis of the disease can be divided into two parts, in the patient with symptoms (early cancer diagnosis) and in the asymptomatic patient (cancer detection). There are no specific symptoms of cancer of the lung. Le Roux (1968) found that only $68 \%$ of his patients presented with chest disease, $13 \%$ complained of symptoms caused by metastases, $12 \%$ of non-specific symptoms such as loss of weight or anorexia without respiratory symptoms, $2 \%$ of such symptoms as neurological or endocrinological changes and $5 \%$ were asymptomatic. When chest symptoms do occur they are those of many other chest diseases. Thus, in all cases of chest disease with symptoms it is important to exclude the possibility of cancer, either as the causative disease or as a concomitant of some other chest disease. The difficulty of diagnosing carcinoma of the bronchus from the clinical symptoms was evident to William Stokes in 1882. In his book, 'A Treatise on the Diagnosis and Treatment of Disease of the Chest', he described how in some cases it was impossible to apply any direct diagnosis; the symptoms were obscure, the physical signs being merely those of solidarity more or less extensive. It was not until a mass produced signs of compression 
on the oesophagus or trachea, or displaced these structures, that the diagnosis became that of a tumour. The presence of superior mediastinal obstruction immediately makes one suspicious of a malignant tumour in the chest, and diagnosis and treatment then become a matter of urgency. In patients with established diseases such as bronchitis and tuterculosis, it is important to examine further any change in symptomatology or failure of response to the appropriate treatment.

The diagnosis of carcinoma of the bronchus in the asymptomatic patient involves the mass screening of individuals, especially those who are at high risk.

\section{Effect of early diagnosis on the prognosis}

In general it can be said that patients who have no symptoms and those who have had symptoms of only a few weeks duration, survive longer. Davies (1966) pointed out that the resectability rate is more than doubled in the asymptomatic patient, but the survival rate shows only a moderate improvement. Even if the survival rates doubled, the proportion dying from lung cancer within 5 years of its discovery would only decrease from about 95 to $90 \%$.

The duration of the presenting symptoms will depend on the site of the primary tumour. On the whole a peripheral tumour is more likely to remain hidden for a longer time than one in the main bronchus, but erosion of a blood vessel or obstruction of a bronchus may cause symptoms at an early stage. Usually a rapidly growing tumour will give symptoms before a more differentiated slow-growing tumour by reason of its size. But the larger the tumour the greater would appear to be the possibility of erosion of a blood vessel and dissemination of the disease.

Reports in the literature have shown some improvement with early diagnosis. Guiss (1960) found that the asymptomatic patient had a better prognosis and, provided the tumour was resectable, its size would appear to have no bearing on the prognosis or duration of life after surgery. Weiss, Boucot \&
Cooper $(1966 \mathrm{a}, \mathrm{b})$ found that the smaller the initial size of the tumour, the greater was the survival for each histological type, whether the tumour was resected or not.

Unfortunately, not all patients who present without symptoms have an early carcinoma. We reported the results of radiotherapy in 513 patients with an inoperable carcinoma of the bronchus (Deeley \& Singh, 1967); twenty-six of these patients $(5 \%)$, had no symptoms, the mass in the lung had keen revealed on routine radiographic examination and the condition at that time was inoperable. The survival rate in these twenty-six patients was not significantly different from the other inoperable cases, at 2 years it was $15 \%$ for both groups, at 5 years it was $7 \%$ for the asymptomatic group and $6 \%$ for those with symptoms.

\section{Associated diseases}

In recent years considerable attention has been focused on the association of malignant diseases in the chest with co-existent non-malignant disease often of a chronic nature.

The development of lung cancer in a chronic bronchitic is too well known to elaborate further. An increase in the severity of symptoms or a change in the symptomatology in these patients demands further investigation. Table 1 gives some idea of the proportion of patients with lung cancer who gave a? history of chronic bronchitis or a chronic cough for each of the main histological types.

In a way the chronic bronchitic is at a disadvantage because he is already diagnosed as having a certain chest disease and may continue to be treated as such even when his symptomatology would warrant further investigation. It is in these patients that routine, regular sputum examination for malignant cells and routine chest radiographs would appear to have an application. The same applies to patients suffering from one of the pneumoconioses (Bidstrup, 1964). Rimington (1971) concluded that persons who smoke ran a higher risk of bronchitis

TABLE 1. History of chronic cough in patients with proved cancer of the lung

\begin{tabular}{ccccc}
\hline & \multicolumn{4}{c}{ Histology } \\
\cline { 2 - 5 } & $\begin{array}{c}\text { Squamous } \\
\text { cell }\end{array}$ & $\begin{array}{c}\text { Anaplastic } \\
\text { tumour }\end{array}$ & Oat cell & $\begin{array}{c}\text { Adeno- } \\
\text { carcinoma }\end{array}$ \\
\hline $\begin{array}{l}\text { No. of patients } \\
\begin{array}{l}\text { No. with bronchitis } \\
\text { or chronic cough }\end{array}\end{array}$ & 396 & 118 & 140 & 26 \\
\multicolumn{1}{c}{$\%$} & 184 & 17 & 59 & 10 \\
\hline
\end{tabular}


than non-smokers and those who developed bronchitis ran a high risk of developing lung cancer.

Of particular interest is the development of mesotheliomata and cancer of the lung in patients working with asbestos. These patients are at a particular risk and warrant frequent examination of the sputum and chest radiographs. Over $60 \%$ of deaths in which astestosis was mentioned had associated bronchial or pleural cancer (Ministry of Labour, 1966). Selikoff, Hammond \& Churg (1968) claimed that astestos exposure and not severe askestosis was associated with cancer of the lung and that the risk was greater in askestos workers who smoked. Wagner (1971) considered that the association tetween asbestos and malignant disease was 'both complex and a cause for concern', the increased amount of askestos being used and the long latent period before tumour development means that there will be increasing problems in years to come.

The possibility of a carcinoma of the bronchus in cases of unresolved pneumonia is, of course, well known to all physicians. The failure of a pneumonic process to resolve rapidly with antibiotics should always lead to further investigation.

Ettman (1968) reported nine cases of pulmonary emphysema or cystic disease of the lung who subsequently developed a carcinoma in the same lote or at the site of the pre-existing anomaly-in several cases the diagnosis was complicated by added infection.

An increase in the number of cases of co-existent carcinoma of the bronchus and pulmonary tuberculosis has keen reported in recent years. This is probably due to the efficiency of antituberculous drugs in increasing the number of patients who will live sufficiently long enough to develop a carcinoma. Deeley (1967) reported seventy-seven cases who had both lesions; other reports have been made by Bobrowitz et al. (1961), Larmi (1967), Sherman, Conant \& Peereboom (1967) and Fontenelle \& Campbell (1970). Failure of a tuterculous lesion to respond to the appropriate antituberculous drugs should lead to further investigation, including sputum cytology, bronchoscopy and drill biopsy, if applicable, to determine whether there is an underlying carcinoma present also. If these fail to produce a satisfactory conclusion and if there is evidence of an increase in size of the lung mass, a thoracotomy is indicated. If carcinoma is confirmed pneumonectomy or lobectomy may te feasible. It is considered that the presence of tuterculosis is not a contra-indication to radical radiotherapy aimed at a cure (Deeley, 1967).

The possibility of a co-existent carcinoma of the bronchus should always be borne in mind in a patient with any chest disease and, in particular, in those who are 40 years and over, have a chronic cough and are heavy smokers.
Symptoms may not be related directly to the chest and the presence of a number of associated extrathoracic signs and symptoms have been reported (Knowles \& Smith, 1960). Various systemic effects from a carcinoma of the bronchus, such as endocrinological and metabolic changes (Cushing's syndrome, gynaecomastia, hypercalcaemia, hyponatraemia, etc.), certain skin manifestations and neuropathies have been described and summaries of these will be found in articles by Azzopardi (1966), Anderson (1971) and Heron (1971). The recognition of these manifestations may result in the diagnosis of the malignant condition at a stage where it is still treatable.

\section{Radiological diagnosis}

A radiograph of the chest remains the best method of distinguishing a mass in the lungs. Tumours as small as $0.3 \mathrm{~cm}$ may be detected in ribfree lung (Spratt, Ter-Pogossian \& Long, 1963; Garland, 1964; Brantigan, 1967) but are often not diagnosed until at least $0.6 \mathrm{~cm}$ diameter. Spratt $e t$ al. (1963) estimated that by this time there had been 26.7 doublings of a $1000 \mu \mathrm{mm}^{3}$ cell. In parts of the lung obscured by bony or mediastinal shadows tumours as large as $2 \mathrm{~cm}$ may remain undetected on a routine chest radiograph. Three medical students at Westminster Hospital, London, recently set out to answer the question 'How much of the lung fields in a chest X-ray film is not obscured by shadows of the rib cage?' Their approach was novel and provided useful information. They cut out the small areas of unobscured lung from prints of the radiographs and compared the weight of these with that of the whole lung field. In patients of 20 years and over the mean percentage of unobscured lung was only $24.5 \%$ (Evans, Levins \& Moorson, 1968).

Lilienfeld \& Koroan (1966) carried out an interesting study on the variability of interpretation of chest $\mathrm{X}$-rays and found that the positive readings of one radiologist were confirmed by another radiologist in from 50 to $60 \%$ of cases, and the negative readings in about $90-95 \%$ of cases; similar degrees of agreement were found when the same radiologist read a series of X-rays twice. The authors concluded that two radiologists should read the radiographs independently to yield the maximum number of suspect cases.

The changes which may be found on radiography vary tremendously and have been described by Rigler (1966) as a homogeneous density, an indistinct dense area, local infiltration along vessels, segmental pneumonic consolidation, apical lesions, a mediastinal mass, hilar enlargement, lobar segmental emphysema, atelectasis and even cavitation. Walske (1966) in a series of 217 resected solitary pulmonary nodules, found that $34 \%$ were malignant and, if 
patients of over 50 years of age were considered, this rose to $53 \%$. Diagnosis of a solitary lesion in the lung can always be difficult and the application of computer technique to the problem is encouraging (Templeton et al., 1967)-this will require the pooling of a considerable amount of information collected from many centres. Bluth (1966) pointed out the importance of abnormalities in the vascular pattern on conventional radiographs and showed that tomography may reveal definite changes in this vascular pattern. Infiltration of the septal lymphatics and veins may be seen extending from the pleural margin in cases of peripheral carcinoma which has metastasized to the adjacent pleural or sub-pleural vessels (Altemus, 1969).

The importance of investigating the whole lungs for possible synchronous double, or even triple, primaries is stressed by Leastedt et al. (1968) who also advise careful follow-up X-rays in the long survivor who is in the potential position of developing a further metachronous primary tumour in the same 'soil'.

Obstruction in a peripheral bronchus may be detected by bronchography and, although not diagnostic of a carcinoma, it may offer sufficient evidence to warrant a thoracotomy (Wilt et al., 1959; Bignall, 1966). The commonest and most conclusive bronchographic sign is abrupt bronchial obstruction according to Mason \& Templeton (1966) and was responsible for diagnosis and localization in $89 \%$ of patients with lesions in major, second and third order bronchi.

Rinker et al. (1968) described the value of bronchographic studies in the investigation of suspected carcinomatous lesions. They distinguished six signs of carcinoma: amputation of the bronchus in which there was distal narrowing with the meniscus pointing away from the hilum at the site of the occlusion (in benign lesions there is proximal widening with the meniscus pointing towards the hilum), sharp cutoff of a bronchus, a stretched or bent bronchus, asymmetrical bronchial narrowing, rat-tail narrowing of a bronchus and a thumb-print indentation of the involved bronchus. In their series of 262 patients, the overall accuracy of examination of lung cancer was $94 \%$ - only one false positive occurred. They discuss the accuracy of each of the six signs, rat-tail narrowing being the least reliable.

Milne (1967) carried out post-mortem arteriographic studies on eighteen cases of carcinoma of the bronchus and found that the blood supply was from both bronchial and pulmonary arteries. The circulation was dependent on the histological type of the tumour. If this technique could be applied to in vivo studies a major step may be made in tumour diagnosis. Routine angiography as a diagnostic measure is not generally accepted in this country
(Simons, 1971). The chest radiograph may reveal a distortion in the lung highly suggestive of malignancy but a positive diagnosis can only be made on histological examination.

\section{Mass radiography service}

The routine chest radiography of large numbers of the population proved to be of immense value in the diagnosis of cases of pulmonary tuberculosis, but the results of such surveys have not been so encouraging when applied to cancer of the lung. Gilbertson (1964) reported a detection rate of one lung cancer in 5378 examinations. Virtama (1962) found a detection rate of $0.41 \%$ for persons examined for carcinoma of the bronchus, but this was increased to $0.89 \%$ for persons over 60 years of age, Brett (1968) found a detection rate of $0.9 \%$. The detection rate will, of course, vary with the type of person examined and will be greatest in the older age group and in persons with a history of chronic bronchitis and smoking.

Brett (1968) has reported the results of a prospective study carried out by the Mass Radiography Service in London. This study has attempted to evaluate the results of 6-monthly chest radiographs. 29,723 men aged 40 years and over had 6-monthly radiographs of the chest over a period of 3 years and were compared with 25,311 who were only radiographed at the beginning and end of the 3-year study. The question asked was whether a 6-monthly radiograph survey improved the prognosis of the disease. It was found that the annual mortality from lung cancer, based on sixty-two deaths in the test group and fifty-nine deaths in the control group, was 0.7 and $0.8 \%$ respectively. The author concludes that 'since early detection by 6-monthly chest radiographs has not significantly reduced the mortality from lung cancer in a population at risk, a policy of such large scale surveys of men in the cancer age would not seem justified, but that the increased discovery of resectable lung cancer by this method forms a reasonable basis for encouraging individuals in high risk groups to make regular use of existing mass radiography facilities'. A later article by the same author (1969) concluded that 'through earlier radiological detection a modest improvement in the prognosis of lung cancer can be achieved'.

Nash, Morgan \& Tomkins (1968) carried out 6-monthly radiographs on 67,400 men aged 45 years and over; their findings seemed to confirm that the prognosis was improved by early diagnosis; they recommended that routine examination should be carried out at intervals not exceeding 6 months.

The cases picked up by mass radiography in the absence of symptoms will include a disproportionate number of cases in which the cancer is slow growing. It is possible that in rapidly growing tumours a cancer may have grown and metastasized and have 
become clinically evident, and even have caused death between the 6-monthly X-ray films. Bidstrup (1964) pointed out that $50 \%$ of lung cancers had no radiological abnormality up to 6 months before death.

The majority of workers have reported disappointing results as a result of chest surveys (Heasman, 1961; Shanks \& Kerley, 1962; Virtama, 1962; Posner, McDowell \& Cross, 1963; Gilkertsen, 1966; Rubin, 1966). It has been proposed by all these workers that routine mass radiography surveys should be directed to men who are in selected high risk groups, over 45 years of age, who are urban dwellers and heavy cigarette smokers. In addition there are some occupations where there appears to be an increased risk of lung cancer. Bidstrup (1964) reported certain occupations where the incidence of lung cancer was greater than among males in the population as a whole; where there is exposure to radiation, the refining of nickel, in the manufacture of bichromates, any work involving asbestos dust, in some processes of the manufacture of coal gas and the mining of haematite. In addition, he added certain industries in which the risk may be greater, in the manufacture of isopropyl alcohol, in iron and steel foundries, in sand blasting and in the manufacture of chrome pigments.

Grzybowski \& Coy (1970) screened 2112 male smokers over the age of 40 years who either suffered from chronic bronchitis, showed long-standing radiographic abnormalities or had recently recovered from pneumonia-by means of chest X-rays and sputum cytology. Seventeen cancers were discovered, eight by X-ray alone, seven by cytology and two by both methods. The authors suggested that both screening methods should be used.

Bignall (1966) made an important summing-up of the use of routine chest radiography, 'It has been proposed on several occasions that men over the age of 45 should be advised to have their chest $\mathrm{X}$-rayed every 6 months, for it is argued that this would result in more patients having the tumour diagnosed at an early stage with consequent improved survival after treatment. However, there is at present no convincing evidence that this does occur and routine radiography at regular intervals has some disadvantages. A man who has a haemoptysis a few weeks after receiving a satisfactory report of a chest $\mathrm{X}$-ray examination may attach little significance to it kecause of this report. He may not seek medical advice until the next routine film is taken and this may show an advanced and inoperable condition. Thus, the gains from early diagnosis in some patients must ke set against possible losses from late diagnosis in others'.

The cost of such routine examinations has been pointed out by several workers. Gilbertsen in 1964 detected one lung cancer in 5378 examinations each of which cost 5 dollars or a total of 26,890 dollars, which was considered to be economically impracticable. Nash et al. (1968) estimated that the cost of finding a potential 4-year survivor from a group of non-smokers, was $£ 990$, but in heavy smokers aged 55 years and over the cost may be as little as $£ 180$.

\section{Cytological diagnosis}

The proportion of positive cytological findings in cases of carcinoma of the bronchus has varied in the literature; it will depend upon the experience of the worker and the number of specimens taken (Ozgelen, Brodsky \& DeGroat, 1965; Nasiell, 1967). Santi \& Carli (1970) carried out a cytological analysis of the sputum of 4500 apparently healthy working people and found five cases of lung cancer.

All workers have stressed the importance of taking several specimens for examination and the proportion of positive specimens increased with the number of examinations made.

There are, of course, differing degrees of concordance between investigators, there being more agreement between workers of the same department (Archer et al., 1966). Screening with two technicians simultaneously is $16 \%$ more effective than with one according to Cardozo et al. (1967).

Not all cancers of the lung will produce malignant cells in the sputum. A peripheral lesion may not communicate with a bronchus or the bronchus may be obstructed so that the cells do not reach the trachea; the patient may be exfoliating cells but there may not be sufficient bronchial secretion to carry this away. Several methods have been devised to increase the secretions of mucus, for example, by the inhalation of aerosol solutions, usually preheated to about $160^{\circ} \mathrm{F}$, of saline and propylene glycol in combination (Berkson \& Snider, 1960; Umiker et al., 1960; Leilop, Garrett \& Lyon, 1961; Lillehei, 1961; Rome \& Olson, 1961; Olsen, Froeb \& Palmer, 1961; Johnson et al., 1962; Fontana et al., 1962; Kim et al., 1963; Frenzel \& Papageorgiou, 1964; Fontana, Olsen \& Woolner, 1964; Fontana et al., 1965; Ozgelen et al., 1965). In a series of over 1000 cases, Fontana, Olsen \& Woolner (1964), have obtained satisfactory specimens of sputum for cytology in $99 \%$ of cases of malignant disease of the lung. Adverse reactions have been rare but bronchospasm may occur when $15 \%$ saline solution is used for asthmatics or severe bronchitics. Takahashi, Hashimoto \& Osada (1967) described the technique of intramuscular injections of chymotrypsin and also used this substance in a nebulizer and reported a considerable improvement in the results.

All cytological studies obtained their best results with large primary tumours which involved the main bronchi. The results are poorer with smaller 
peripheral or metastatic tumours in the lung but even in these cases the results can be improved with induced sputum examination.

There have been several attempts to improve the results of examination of the specimens obtained. The material may be concentrated by dissolving the mucus with various agents such as urea, hydrogen peroxide, detergents, a variety of enzymes, hyaluronidase, lysozyme, papain, trypsin and chymotrypsin and then spinning down in a centrifuge (Pharr \& Farber, 1962). However, there has teen some dissatisfaction with such methods either because they were complicated, time-consuming and expensive or because there was no real improvement in the percentage of positive smears; in addition it has been reported that adenocarcinoma and undifferentiated carcinoma cells were destroyed (Umiker, Young \& Waite, 1958; Chang \& Russell, 1964). Concentration of the cells by millipore filtration and then solution of the membrane by ethyl acetate has been described by Fields et al. (1966), Liu (1966), Russell \& Chang (1967). Garland (1964) described methods of fractionation which segregate cells into different fractions according to the cell dimensions so that there is a relatively uniform cytologic composition in each smear. Russell \& Chang (1967) developed a technique of emulsification and membrane dissolution which could be suitable for screening by an automated mechanical device.

In any series of examinations by cytology there will be a small proportion of false positives. This will, of course, vary with the number of specimens examined from each patient but is usually about $3 \%$ (Parker \& Reid, 1960; Hinson \& Kurer, 1963; Russell et al., 1963; Frenzel \& Papageorgiou, 1964; Gwynne \& Parrish, 1964; Laurie, 1966). Davies (1966) has estimated the incidence of false positives from the literature and has shown that the causes may be tuberculosis, squamous metaplasia, inflammatory processes, bronchiectasis, lung abscess or pneumonitis; out of 2539 positive cases who were established cytologically seventy-six had a false positive report. It is unusual for the trained cytologist to miss malignant cells on the slide; the commonest reason for false negative results is the poor quality of the sputum specimen because of lack of a deep cough, bronchial obstruction, faulty collection of the specimen or an insufficient number of specimens.

It is often possible to diagnose the histological type from the cytology. Hinson \& Kuper (1963) found positive smears in $60 \%$ of squamous tumours, $42 \%$ of adenocarcinomas, $36 \%$ of oat-cell and $46 \%$ of undifferentiated tumours. Similar results were obtained by Parker \& Reid (1960), Rome \& Olson (1961) and Koss, Melamed \& Goodner (1964).

There have been several reports of passing a nylon brush through a bronchoscope to a suspicious area shown on the chest radiograph. The course of the tip of the brush is followed on an image intensifier and TV system (Hattori et al., 1964; Hattori et al., 1965; Hattori et al., 1966a; Fennessy, 1966; Hattori et al., 1966b; Tsubio et al., 1967; Hattori \& Matsuda, 1971). No complications have been reported after this procedure (Umiker, 1961). As could be expected, the larger the tumour mass the greater was the possibility of getting a positive smear. Hattori et al. (1964) obtained positive results in twenty-nine out of thirty-three peripheral lesions. They were unable to diagnose cylindroma or adenoid-cystic carcinoma because the tumour was covered by bronchial epithelium. The same authors stated that Papanicolau's criteria do not seem satisfactory for the cells of an early peripheral cancer which do not always show hyperchromasia but reveal rather fine and evenly distributed chromatin. They have devised a new criterion for the diagnosis of cancer cells and have compared the electron microscope and histological findings. Hattori \& Matsuda (1971) reported the use of the TV brushing method for early diagnosis in small peripheral lung lesions of less than $2.0 \mathrm{~cm}$ diameter-positive cytology was found in 142 out of 171 confirmed primary lung cancers.

Cytology may be positive in patients with in sitif or early invasive lesions (Melamed, Koss \& Clifton? 1963; Pearson, Thompson \& Delarne, 1967). Whilfi Pearson et al. (1967) thought there was no evidence to suggest that the tumour was multifocal, Ryan, McDonald \& Clagett (1959) found carcinoma in situ in the opposite lung in $12 \%$ of cases in which resection had been carried out for a bronchogenic carcinoma and Auerbach et al. (1957) found on serial block disection, a carcinoma in situ in $75 \%$ of heavy smokers and an equally high incidence in patients known to have bronchogenic carcinoma.

\section{Pre-symptomatic diagnosis by cytology}

It has been suggested that routine cytology may detect cases of lung cancer at an early stage before clinical symptoms have developed and that it could be used as a screening procedure. Koivuniemi \& Holsti (1967) carried out cytological screening in 970 males between the age of 35 and 55 years and concluded that 'sputum mass screening for early diagnosis of lung cancer is at least as useful as cytological mass studies for the detection of gynaecological cancer'. Scott (1965) in a series of investigations on coal miners with lung cancer, pneumoconiosis and progressive massive fibrosis, found that cytology was not helpful in differentiating peripheral lesions. Andrews \& Rosser (1964) thought that cytology failed as a simple screening test and was best reserved for cases where other methods of investigation have failed.

There is a distinct clinical problem of the further 
management of those patients who have positive cytology and in whom there is no radiological evidence of tumour and where no tumour or even suspicious areas are seen on bronchoscopy. Melamed, Koss \& Clifton (1963) have suggested a useful plan of campaign for these patients:

(1) Cytological examination must be unequivocal -two different specimens.

(2) Rule out carcinoma of nasopharynx, mouth, throat, laryn $x$ and oesophagus.

(3) Look for possible localizing physical signs.

(4) X-ray stereoscopic, sagittal and lateral views of the chest, inspiration-expiration X-ray, fluoroscopy with barium swallow.

(5) Aspirates of bronchial secretions-two bronchoscopes-one each side.

(6) Selective bronchoscopic biopsies from major bronchi and accessible segmental branches.

(7) Bronchography-a rapidly clearing contrast.

(8) Tomography and angiography sometimes of value.

(9) Exploratory thoracotomy without pre-operative localization is unjustified as it will be equally hard to find at open thoracotomy; in addition the effects of surgery will obscure subsequent radiological changes.

We should now add radio-isotope scanning as a possible means of detecting the tumour mass.

While Pearson et al. (1967) thought that there was good evidence to indicate that the natural history of lung cancer in these early stages may extend over a period of years before the tumour becomes manifest on a chest radiograph, and that to repeat the investigation at too frequent an interval may exhaust the enthusiasm of both patient and doctor, Lerner et al. (1961) suggested that by the time that the usual radiological evidence of tumour obstruction, obstructive emphysema or atelectasis, with or without infection, and mediastinal shift had occurred, the carcinoma was no longer at an early stage and the resultant prognosis would be poor. These authors suggested routine monthly radiographs and 3monthly tomography, bronchography and bronchoscopy, until the site of the lesion became evident. Umiker (1971) stressed that in all cases where there was positive sputum cytology and no demonstrable lung lesion, extra-pulmonary sites such as the buccal cavity, pharynx, nasopharynx and larynx should be carefully investigated.

As a routine procedure it is suggested that screening is reserved for 'high risk' patients; that is, males over 40 years of age and heavy smokers (Woolner, Anderson \& Bernatz, 1960; Melamed, Koss \& Clifton, 1963; Rubin, 1966) and also for patients who present with unexplained chest symptoms. It is suggested that, in these patients, tests may be carried out twice yearly or even at 3-monthly intervals (Rubin, 1966).

These tests are, however, time consuming and, at the present moment it is too expensive to carry out a routine screening test on all patients. It is possible that future developments may include the automatic screening of concentrated specimens of sputum.

\section{Radio-isotope lung scanning}

Intravenous injection of a radio-active material may be used to scan the lung as a method of detecting early disease. The technique uses $200-300 \mu \mathrm{Ci}$ of 131I-iodinated macro-aggregated human serum (Maxfield, Hatch \& Nelson, 1971), but technetium99 macro-aggregated albumen (Webber, Bennett \& Suprenet, 1966), indium-113m iron hydroxide particles (Stern et al., 1966) and technetium-labelled ferric hydroxide macro-aggregate (Yano et al., 1969) have also been used.

In the detection of malignant disease of the lung, Maxfield, Hatch \& Ochsner (1966) found that in 100 confirmed cases of bronchogenic carcinoma a positive scan was found in ninety-six. In five of the patients where the scan was negative the radiograph revealed a small peripheral or Pancoast tumour and in one patient where the tumour involved the carina both radiograph and scan were negative. In four cases the chest film was normal and the lung scan positive. The greater accuracy of lung scan in central lesions in comparison with peripheral lesions was also noted by Johnson, Sagerman \& Jacox (1968), Maynard et al. (1969), and Ernst, Krüger \& Vessal (1969). Maynard et al (1969) reporting the results in forty-three patients found that the radiographic changes were commensurate with the scans in twenty-three cases but in twenty cases the scan changes were disproportionately greater than those seen on X-ray. They concluded that except in isolated cases, lung scanning will probably be of little value in early diagnosis. It would seem, however, to be worth trying in the patient who has malignant cells present in the sputum but where radiological examination and bronchoscopy fail to reveal the site of the lesion-the finding of a positive lung scan would warrant a thoracotomy on that side.

\section{Other investigations}

There are other special investigations which may help to make a definite diagnosis at an early stage in patients presenting with chest signs or symptoms which suggest the possibility of a lung primary.

\section{Bronchoscopy}

When a mass is seen on the chest radiograph a bronchoscopy must be performed to determine the site and extent of the tumour and its operability and to obtain a specimen of tissue for histology examination. 
D'Abreu (1958) estimated that $75 \%$ of lung cancers are situated centrally in an area of the bronchial tree visible at bronchoscopy, Barth, Siegel \& Luder (1968) confirmed this and found that $25 \%$ of tumours were peripheral in a series of 2767 bronchoscopies for lung cancer and Zajaczkowska, Krakowka \& Kozakow (1968) in a series of 609 bronchoscopies found peripheral tumours in $19 \%$.

The macroscopic appearances of the tumour were described by Finzi, Tenca \& Merelli (1968), 51\% were exophytic, $46 \%$ infiltrating, and rather surprisingly only $3 \%$ were described as ulcerative. In their large series Barth et al. (1968) obtained an overall positive biopsy rate of $81.4 \%$; in centrally placed tumours $92.5 \%$ were verified histologically and in peripheral tumours the rate was $48.9 \%$. Similar overall results were obtained by Anderson (1970), satisfactory material being obtained by biopsy in $82 \%$ of tumours. Methods of obtaining cytological proof by means of bronchoscopy and TV brushing techniques have already been described.

The normal and abnormal findings on bronchoscopic examination have been described fully by Benedict (1959) who detailed the bronchoscopic findings, methods of evaluating the extent of the disease and the criteria determining the operability of the lesion. Putney (1968) gave an excellent review of the techniques of bronchoscopy, the bronchoscopic appearances, methods of biopsy and the contra-indications and complications. Stradling's book (1968) is profusely illustrated with excellent colour photographs taken at bronchoscopy.

It is, of course, important that the bronchoscopist is familiar with the endobronchial findings and the surgeon who will operate is obviously the best person to assess operability. These points were stressed by Benedict (1959); the clinician who does only an occasional bronchoscopy was not competent to assess whether the tumour was technically operable. Haldy, Jones \& Strickland (1970) pointed out the dangers of accepting a negative bronchoscopy report in the presence of suspicious radiographic findings. They reviewed fifty-seven cases of primary carcinoma of the bronchus where the bronchoscopy failed to reveal tumour, either because the tumour was unfavourably placed, for example, in the right upper lobe bronchus, the bronchus was blocked or encircled by growth which had not penetrated the bronchial wall or because there was excessive secretion in the lumen. Failure to appreciate the limitations of the technique may cause considerable delay in arriving at a diagnosis and the start of definitive radical treatment; an operable tumour may become inoperable.

There are fortunately few serious complications of bronchoscopy. Wilson (1969) described the measures to be taken if massive bleeding should occur; the patient is placed in the Trendelenberg position, the $\stackrel{\varnothing}{\circ}$ bronchoscope is kept in position so that packing can $C$ be applied, blood sucked out and oxygen adminis- $\vec{F}$ tered by a catheter beyond the bleeding area. Troublesome bleeding is more likely to be encountered in cases of superior vena caval obstruction and the majority of these patients are unsuitable for bronchoscopy; if there is strong clinical evidence of $\propto$ tumour radiotherapy should be started immediately. कै Relief of venous congestion often occurs quite early $\vec{O}$ on in treatment and it may then be possible to carry out bronchoscopic examination and to obtain a representative biopsy of the tumour.

Lung function tests performed at the time of $\mathscr{C}$ bronchoscopy may be used to assess the differential 3 function of separate lobes; whilst they are of most $\vec{\infty}$ use in assessing operability they may help to deter- of mine the involved lobe in those cases where cytology or is positive but no tumour is seen radiographically or $\omega_{\omega}$ on bronchoscopic examination (Sanderson et al., 은 1970).

The range of the bronchoscopic examination has $\vec{c}$ been considerably extended by the use of the flexible fiberoptic bronchoscope. Ikeda (1970) described the specifications, characteristics and techniques employed with this apparatus and Fennessy (1970) has $\overrightarrow{0}$ demonstrated its uses in the selective catheterization $N$ of segmental and subsegmental bronchi. Thos apparatus could ke used whenever injection by routine bronchography fails to fill a segment; in patients with restriction of respiratory reserve in whom routine bronchography is contraindicated; $\stackrel{\circ}{\mathbb{D}}$ to obtain washings, brushings or biopsy from the bronchial tree beyond the limits of the ordinary bronchoscopy and to instill medicants to selective segments of the bronchial tree. This instrument will also permit catheterization of small bronchi where a fluoroscopically guided catheter has been unsuccessful.

Diagnostic bronchoscopy demands careful and meticulous investigation; this can best be carried out with light anaesthesia which allows more time for full examination and for taking suitable photographs which may te useful for comparison with subsequent findings (Stradling, 1971).

\section{Scalene node biopsy \\ Nohl in 1958 suggested that where no lymph nodes} were palpable, the right supraclavicular region should always be explored irrespective of whether the chest lesion was on the left or the right. Aikins (1959) found that the scalene nodes were positive in eight out of thirty-five patients with primary carcinoma of the bronchus. Palumbo \& Sharpe (1963) found that the biopsy was positive in $91 \%$ of palpable nodes and $12 \%$ of non-palpable nodes-where the growth was clinically operable scalene nodes were positive in no 
less than $52 \%$. Leckie, McCormack \& Walbaum (1963) reported that where no nodes were palpable in the neck subsequent histology of the scalene node was positive in only one case out of eight and they considered that biopsy should not be carried out routinely. Morgan \& Scott (1962) reported positive scalene fat pad biopsy in $12 \%$ of cases of carcinoma but Nohl-Oser (1971) thought that scalene node biopsy was only indicated in the presence of palpable nodes.

\section{Mediastinoscopy}

The value of mediastinoscopy in diagnosing early suspicious lesions in the chest has been reviewed by Harken et al. (1954), Steele \& Marable (1959) and Nohl-Oser $(1965,1968)$. In a review of the value of mediastinoscopy, Nohl-Oser (1971) considered that mediastinoscopy had superseded scalene node biopsy because:

(a) Both sides of the mediastinum could be explored.

(b) Biopsies can be obtained nearer to the primary lesion and thus the positive yield is greater.

(c) An indication of the resectability can be obtained.

\section{Drill biopsy}

Peripheral lesions of the lung may be diagnosed by histological examination of material obtained from a drill through the chest wall, or by an aspiration needle. Deeley (1960) found a correct diagnosis in $85 \%$ of patients whose lesions were biopsied in this way, and subsequent reports on the use of a high-speed drill to obtain specimens have been made by Deeley \& Pollock (1966), Steel \& Winstanley (1967) and Steel (1971). In my hands a high-speed drill has been found to be more efficient than other needles which depend on aspiration, such as those used by Manfredi et al. (1960), Sabour et al. (1960), Aronovitch et al. (1963) and Smith (1965).

The use of these methods of biopsy has caused some concern over the possible dangers of spread of malignant cells into the blood stream causing distant metastases. Burn, Deeley \& Malaker (1968) carried out drill biopsies on a series of malignant tumours growing in rats and concluded that the length of survival of rats was not shortened by the procedure, when compared with a group of control rats and there was no increase in the incidence of circulating tumour cells, distant metastases or recurrent tumours after local excision.

A peripheral mass shown on a radiograph, which is outside the scope of biopsy by bronchoscopy, should have a drill biopsy to determine its character.

\section{Conclusions}

It is very much a matter of chance whether the patient will present at hospital for treatment when the disease is still at an early stage. The very nature of the disease is in most cases insidious,; in the few cases where symptoms are immediate and severe, such as superior mediastinal obstruction, the condition becomes one of emergency and treatment is instituted at an early stage. There must be a stage when the tumour is small, where erosion of a blood vessel has not occurred and where treatment to the chest either by surgery or radical radiotherapy could eliminate the disease. The longer the delay before treatment, the greater is the chance of distant metastases.

A greater awareness of the probable seriousness of any chest symptoms may result in earlier diagnosis. This demands awareness on the part of the patient, who must report any untoward symptoms to his general practitioner, who in his turn must also show an increased awareness and refer suspicious cases for further diagnosis by X-ray, cytology, etc. In addition, any investigation at hospital must be carried out as expeditiously as possible. Failure of response to conventional therapy aimed at a benign condition should alert the physician to the possibility of an underlying malignancy and the possibility of co-existent diseases must always be borne in mind.

In the patient with symptoms, every effort should be made to exclude the possibility of malignancy; it would be a wise maxim to exclude malignancy before a firm diagnosis of a non-malignant condition is made. This is particularly so in the older patient, especially if he has a history of smoking or chronic cough.

It would be desirable to aim at detection of the disease before symptoms develop. At present, it is not practical to carry out large mass surveys of sputum cytology and this method should be reserved for the high risk patient. The most effective method of diagnosis at present is the chest radiograph, and facilities should be available for immediate chest $\mathrm{X}$-ray of patients with suspicious symptoms and the interpretation of the film by an expert radiologist. Associated with this is the need for special investigations such as bronchoscopy, mediastinoscopy and drill biopsy in patients with a radiologically demonstrated mass.

At the Ninth International Cancer Congress held in Tokyo in 1966 it was pointed out by Grunze that at present there was no single technique or combination of techniques available for the detection of lung cancer that provide results comparable with those in the early detection of cervix, oral, colon-rectum or breast cancer.

Even if there is a great improvement in the methods aimed at procuring earlier diagnosis it is 
possible that the results of treatment will not be dramatically improved, because of the very high frequency of metastatic spread even with very small tumours. Developments in the treatment of this disease must aim, not only at the extirpation of the primary disease in the chest, but also at possible metastases. Unfortunately, no such method exists at present; the administration of cytotoxic drugs at the time of surgery or radical radiotherapy to the chest has not materially altered the survival rates.

The chances of getting an early diagnosis are not good and there appears to be no immediate hope of improving the survival rate as a result of treatment so we must look to other methods. It is a wise saying that 'Prevention is better than cure' and it becomes more necessary that efforts are made to prevent the occurrence of the disease. Already we have evidence that it is preventable and we know of at least one major cause - tobacco smoking. There are several excellent articles incriminating this aetiological factor, and the reader is referred to the authoritative reports from The Royal College of Physicians in 1962 and 1971 and the United States Department of Health, Education and Welfare in 1964, 1967 and 1968. It is possible that other aetiological factors exist, and increased effort must be made to determine what they are and if possible to remove them.

\section{References}

Aikens, R.L. (1959) Scalene node biopsy. Canadian Medical Association Journal, 81, 891.

Altemus, R. (1969) Localized interlobar septal lines in bronchogenic carcinoma. Journal Thoracic and Cardiovascular Surgery, 57, 380.

Anderson, G. (1971) Associated changes with lung cancer. Endocrine syndromes. In: Modern Radiotherapy-Carcinoma of the Bronchus (Ed. by T. J. Deeley). Butterworths, London.

Anderson, H.A. (1970) Lung biopsy via the bronchoscope. Annals of Otology. 79, 933.

ANDREws, G.S. \& Rosser, T. (1964) Clinical value of exfoliative cytology in neoplasia of the lung. Thorax, 19, 279.

Archer, P.G., Koprowska, I., McDonald, J.R., Naylor, B., Papanicolaou, G.N. \& Umiker, W.O. (1966) The study of variability in the interpretation of sputum cytology slides. Cancer Research, 26, 2122.

Aronovitch, M., Chartier, J., Kahana, L.M., Meakins, J.F. \& Groszman, M. (1963) Needle biopsy as an aid to the precise diagnosis of intrathoracic disease. Canadian Medical Association Journal, 88, 120.

Auerbach, O., Geve, J.B., Forman, J.B., Petrick, J.G., Smolin, H.J., Muehsam, G.E., Kassouny, D.Y. \& Stout, A.P. (1957) Changes in the bronchial epithelium in relation to smoking and cancer of the lung. New England Journal of Medicine, 97, 256.

Azzopardi, J.G. (1966) Systemic effects of neoplasia. In: Recent Advances in Pathology (Ed. by C.V. Harrison), 8th edn. Churchill, London.

Barth, L., Siegel, S. \& Luder, M. (1968) Endoscopic diagnosis of bronchial carcinoma. Archives Geschwulstforsch, 32, 81 .

BENEDICT, E.B. (1959) The value of bronchoscopy in determining the inoperability of carcinoma of the lung. Journal of Thoracic Surgery, 37, 646.
Berkson, D.M. \& Snider, G.L. (1960) Heated hypertonic aerosol in collecting sputum specimens for cytological diagnosis. Journal of the American Medical Association, 173, 135.

BidstRUP, P.L. (1964) The use of radiology in the early detection of lung cancer as an industrial disease. British Journal of Radiology, 37, 337.

BigNALL, J.R. (1966) Early diagnosis of bronchial carcinoma. British Medical Journal, 1, 341.

BluTH, I. (1966) Laminagraphic studies of the vascular patterns in cancer of the lung. American Journal of Roentgenology, 98, 397.

Bobrowitz, I.D., Elkin, M., Evans, J.C. \& Lin, A. (1961). Effects of direct irradiation on the course of pulmonary tuberculosis. Diseases of the Chest, 40, 397.

Brantigan, O.C. (1967) Complacency in carcinoma of the lung. Diseases of the Chest, 52, 173.

BRETT, C.Z. (1968) The value of lung cancer detection by sixmonthly chest radiographs. Thorax, 23,414 .

BretT, C.Z. (1969) Earlier diagnosis and survival in lung $\stackrel{\oplus}{\infty}$ cancer. British Medical Journal, 4, 260.

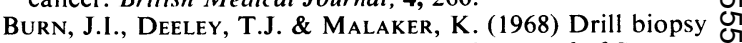
and the dissemination of cancer. British Journal of Surgery, 55, 628 .

Cardozo, P.L., DeGraaf, E., De Boer, K.J., Doesburg, N. O \& KAPSENBERG, P.D. (1967) The results of cytology in 100 patients with pulmonary malignancy. Acta Cytologica, 11, 120.

Chang, S.C. \& Russell, W.O. (1964) A simplified and rapid filtration technique for concentrating cancer cells in sputum. Acta Cytologica, 8, 348.

D'AbreU, A.L. (1958) A Practice of Thoracic Surgerg $\vec{\theta}$ Arnold, London.

DAvies, D.F. (1966) A review of detection methods for thr early diagnosis of lung cancer. Journal of Chronic Diseas $19,819$.

DeELEY, T.J. (1960) Drill biopsy results with a high speed pneumatic drill. Acta Unio Internationale Contre le Cancer, 16, 338 .

DEELEY, T.J. (1967) The treatment of carcinoma of the bronchus. British Journal of Radiology, 40, 801.

DeEley, T.J. \& LiNE, D. (1969) Solitary metastases in carcinoma of the bronchus. British Journal of Diseases of the Chest, 63, 150.

DeEley, T.J. \& Pollock, D.J. (1966) Experiences with a high speed pneumatic drill biopsy machine. British Journal of Cancer, 20, 442.

DeEley, T.J. \& Rice Edwards, J.M. (1968) Radiotherapy in the management of cerebral secondaries from bronchial carcinoma. Lancet, i, 1209.

DeEleY, T.J. \& SiNGH, S.P. (1967) Treatment of inoperable carcinoma of the bronchus by megavoltage X-rays. Thorax, 22, 562.

ETtMAN, I.K. (1968) Bullous disease of lung and bronchogenic carcinoma. Southern Medical Journal, 61, 743.

Ernst, H., Kruger, J. \& Vessal, K. (1969) Lung scanning as a screening method for cancer of the lung. Cancer, 23, $\mathrm{N}$ 508.

Evans, R.J., Levins, C.T. \& Moorson, D. (1968) The radio- N graphic visibility of the lung fields. British Journal of $N$ Radiology, 41, 801.

FENNESSY, J.J. (1966) Bronchial brushing in the diagnosis of peripheral lung lesions. American Journal Roentgenology, 98, 474.

FENNESSY, J.J. (1970) Selective catheterization of segmental $\stackrel{\mathscr{S}}{+}$ bronchi with the aid of a flexible fiberoptic bronchoscope. Radiology, 95, 689.

Fields, M.J., Martin, W.F., Young, B.L. \& Tweedale $\overrightarrow{\mathbb{D}}$ D.N. (1966) Application of the Nedelkoff-Christopherson 
millipore method of sputum cytology. Acta Cytologica, $10,220$.

Finzi, A., Tenca, G. \& Merelli, B. (1968) Bronchoscopic findings in bronchial tumours. Statistical considerations in 242 cases. Annals of Laryngology, 67, 452.

Fontana, R.S., Carr, D.T., Woolner, L.B. \& Miller, F.T. (1962) An evaluation of methods of inducing sputum production in patients with suspected cancer of the lung. Proceedings of Staff Meetings of the Mayo Clinic, 37, 113.

Fontana, R.S., CarR, D.T., Woolner, L.B. \& Miller, F.T. (1965) Value of induced sputum in cytologic diagnosis of lung cancer. Journal of American Medical Association, 191, 134.

Fontana, R.S., Olsen, A.M. \& Woolner, L.B. (1964) Recent advances in the diagnosis of bronchogenic carcinoma. Medical Clinic, North America, 48, 911.

Fontenelle, L.J. \& CAMpbell, D. (1970) Co-existing bronchogenic carcinoma and pulmonary tuberculosis. Annals of Thoracic Surgery, 9, 431.

Frenzel, H. \& Papageorgiou, A. (1964) Malignant cells in the sputum in coin lesions of the lung. German Medical Monthly, 9, 234.

GARLAND, L.H. (1964) The diagnosis of cancer-radiology. California Medicine, 100, 397.

GilbertSEN, V.A. (1964) X-ray examination of the chest. Journal of the American Medical Association, 195, 655.

GruNZE, H. (1967) Evaluation of techniques in cancer detection and lung cancer. In: Proceedings of the Ninth International Cancer Congress (Ed. by R. J. C. Harris). SpringerVerlag, Berlin.

GrzybowsKi, S. \& CoY, P. (1970) Early diagnosis of carcinoma of the lung. Cancer, 25, 113.

Guiss, L.W. (1960) A 5-year follow-up of roentgenographically detected lung cancer subjects. Cancer, 13, 82.

GWYNNE, J.F. \& PARRISH, V. (1964) A survey of pulmonary cytology. New Zealand Medical Journal, 63, 17.

Haldy, W., Jones, P. \& Strickland, B. (1970) Bronchoscopy and the chest X-ray. Postgraduate Medical Journal, 46, 40.

Harken, D.E., Black, H., Clauss, R. \& Farrand, R.E. (1954) Simple cervico-mediastinal exploration for tissue diagnosis of intrathoracic disease with comments on recognition of inoperable carcinoma of the lung. New England Journal of Medicine, 251, 1041.

Hattori, S. \& Matsuda, M. (1971) TV brushing method for early diagnosis of small peripheral lung cancer. In: Modern Radiotherapy-Carcinoma of the Bronchus (Ed. by T. J. Deeley). Butterworths, London.

Hattori, S., Matsuda, K., Sugiyama, T. \& Matsuda, H. (1964) Cytologic diagnosis of early lung cancer. Diseases of the Chest, 45, 129.

Hattori, S., Matsuda, M., Sugiyama, T. \& Terazawa, T. (1965) Some limitations of cytologic diagnosis of small peripheral lung cancers. Acta Cytologica, 9, 431.

Hattori, S., Matsuda, M., Sugiyama, T., Terazawa, T. \& W ADE, A. (1966a) Some limitations of cytologic diagnosis of small peripheral lung cancer. Annual Report of the Centre of Adult Diseases, Osaka, Japan, 6, 81 .

Hattori, S., Matsuda, K., Komatsu, T. \& Tateishi, R. (1966b) A cytologic diagnosis of early lung cancer in reference to electron microscopic and histologic findings. Annual Report of the Centre of Adult Diseases, Osaka, Japan, 6, 89.

Heasman, M.A. (1961) Mass miniature radiography. Studies on Medical and Population Studies, No. 17, HMSO, London.

Heron, J.R. (1971) Associated changes with lung cancer: neuromuscular syndromes. In: Modern RadiotherapyCarcinoma of the Bronchus (Ed. by T. J. Deeley). Butterworths, London.
Hinson, K.F.W. \& Kuper, S.W.A. (1963) The diagnosis of lung cancer by examination of the sputum. Thorax, 18, 350.

IKEDA, S. (1970) Flexible bronchofiberscope. Annals of Otalaryngology, 79, 916.

Johnson, T.R., Cohen, B.M., Crandall, C. \& Sonio, O. (1962) Aerosol-induced sputum: an effective, inexpensive, method for nebulization of a super-heated mixture of 40 percent propylene glycol in isotonic saline. Diseases of the Chest, 42, 251.

Johnson, P.M., Sagerman, R.H. \& Jacox, H.W. (1968) Changes in pulmonary arterial perfusion due to intrathoracic neoplasia and irradiation of the lung. American Journal of Roentgenology, 102, 637.

Kim, B.M., Froeb, H.P., Palmer, L. \& Lloyd, .S.J (1963) Clinical experience with cytologic examination of sputum obtained by heated aerosols. American Review of Respiratory Diseases, 87, 836.

KNowles, J.H. \& Smith, L.H. (1960) Extrapulmonary manifestations of bronchogenic carcinoma. New England Journal of Medicine, 262, 505.

Koivuniemi, A.P. \& Holsti, L.R. (1967) Cytologic population screening in the early detection of lung cancer. Annales Medicinae Internae Fenniae, 56, 65.

Koss, L.G., Melamed, M.R. \& Goodner, J.T. (1964) Pulmonary cytology-a brief survey of diagnostic results. Acta Cytologica, 8, 104.

LARMI, T.K.I. (1967) Co-existent pulmonary tuberculosis and cancer of the lung. Scandinavian Journal of Thoracic and Cardiovascular Surgery, 1, 118.

LAURI, W. (1966) Sputum cytology in the diagnosis of bronchial carcinoma. Medical Journal of Australia, 1, 205.

Leafstedt, S.W., Sweetman, W.R., Chester, C.L. \& THORPE, J.D. (1968) Multiple primary neoplasm of the lung. Journal of Thoracic and Cardiovascular Surgery, 55, 626.

LeCKie, W.J.H., McComaCK, R.J.M. \& Walbaum, P.R. (1963) The case against routine scalene node biopsy in bronchial carcinoma. Lancet, i, 853.

Leilop, C., Garrett, M. \& Lyon, H.A. (1961) Evaluation of technique and results for obtaining sputum for lung carcinoma screening: A study by blind technique. American Review of Respiratory Diseases, 83, 803.

Lerner, M.A., Rosbach, H., Frank, H.A. \& Fleischner, F.G. (1961) Radiologic localization and management of cytologically discovered bronchial carcinoma. New England Journal of Medicine, 264, 480.

LE Roux, B.T. (1968) Bronchial Carcinoma. Livingstone, Edinburgh.

Lilienfeld, A.M. \& Koroan, B. (1966) Study of variability in the interpretation of chest X-rays in the detection of lung cancer. Cancer Research, 26, 2145.

LILLEHEI, J.P. (1961) Sputum induction with heated aerosol inhalants for the diagnosis of tuberculosis. American Review of Respiratory Diseases, 84, 276.

Line, D. \& Deeley, T.J. (1971) Palliative therapy. In: Modern Radiotherapy-Carcinoma of Bronchus (Ed. by T. J. Deeley). Butterworths, London.

Liu, W. (1966) Fluorescence microscopy in exfoliative cytology. Acta Cytologica, 10, 368.

Manfredi, G., Buckley, ili, C.E., Patrick, R.L., Barry, W.F. \& Sieker, H.O. (1960) Lung needle biopsy in the evaluation of diffuse pulmonary disease. American Review of Respiratory Diseases, 82, 800.

MAXField, W.S., Hatch, Jr, H.B. \& OChSNer, J.L. (1966) Perfusion lung scanning in evaluation of patients with bronchogenic carcinoma. Surgical Clinics of North America, 46, 1389.

Maxfield, W.S., Hatch, Jr, H.B. \& Nelson, J.R. (1971) Forecast of prognosis after radiotherapy perfusion lung scanning. In: Modern Radiotherapy-Carcinoma of the Bronchus (Ed. by T. J. Deeley). Butterworths, London. 
Mason, W.E. \& Templeton, A.W. (1966) Bronchographic signs useful in diagnosis of lung cancer. Diseases of the Chest, 49, 284.

Maynard, C.D., Miller, R.P., Heaphy, Jr, L.J. \& Whitley, J.E. (1969) Pulmonary scanning in bronchogenic carcinoma. Radiology, 92, 903.

Ministry OF LABOUR (1966) Annual report of HM Chief Inspector of Factories on Industrial Health. HMSO, London.

MiLne, E.N.C. (1967) Circulation of primary and metastatic pulmonary neoplasms: post-mortem microarteriographic study. American Journal of Roentgenology, 100, 603.

Melamed, M.R., Koss, L.G. \& Clifton, E.E. (1963) Roentgenologically occult lung cancer diagnosed by cytology. Cancer, 16, 1537.

Morgan, W.S. \& ScotT, S.M. (1962) A critical re-appraisal of scalene fat pad biopsies. Journal of Thoracic and Cardiovascular Surgery, 43, 548.

MORRISON, R. \& DEELEY, T.J. (1960) Inoperable cancer of the bronchus treated by megavoltage X-ray therapy. Lancet, ii, 618.

NASH, F.A., Morgan, J.M. \& Tomkins, J.C. (1968) South London lung cancer study. British Medical Journal, 2, 715.

Nasiell, M. (1967) Diagnosis of lung cancer by aspiration biopsy and a comparison between this method and exfoliative cytology. Acta Cytologica, 11, 114.

NoHL, H.C. (1958) The value of scalene node biopsy in intrathoracic disease. British Journal of Tuberculosis, 52, 286

NoHL-OSER, H.C. (1968) Mediastinoscopy. In: Operative Surgery (Gen. Ed., C. Rob and R. Smith), Thorax (Ed. by W. P. Cleland). Butterworths, London.

Nohl-Oser, H.C. (1965) Mediastinoscopy. British Medical Journal, 1, 1167.

NoHL-OsER, H.C. (1971) Associated changes with lung cancer, neuromuscular syndromes. In: Modern Radiotherapy-Carcinoma of the Bronchus (Ed. by T. J. Deeley), Butterworths, London.

Olsen, C.R., Froeb, H.F. \& Palmer, L.A. (1961) Sputum cytology after inhalation of heated propylene glycol; a clinical correlation. Journal of the American Medical Association, 178, 668.

Ozgelen, F.N., Brodsky, S.L. \& DeGroat, A. (1965) An examination of the merits and the intrinsic limitations of exfoliative cytology in 465 cases of lung cancer. Journal of Thoracic and Cardiovascular Surgery, 49, 221.

Palumbo, L.T., Sharpe, W.S. (1963) Evaluation of scalene node biopsy. Surgery, 53, 639.

PARKer, R.E. \& ReID, J.D. (1960) Five-year survey of results of cytological examination for lung cancer. New Zealand Medical Journal, 59, 68.

Pearson, F.G., Thompson, D.W. \& Delarne, N.C. (1967) Experience with the cytologic detection, localization and treatment of radiographically undemonstrable bronchial carcinoma. Journal of Thoracic and Cardiovascular Surgery, 54, 371.

Pharr, S.L., Farber, S.M. (1962) Cellular concentration of sputum and bronchial aspirations by tryptic digestion. Acta Cytologica, 6, 447.

Posner, E., McDowell, L.A. \& Cross, K.W. (1963) Place of mass radiography in relation to lung cancer in men. British Medical Journal, 2, 1156.

Putney, F.J. (1968) Bronchoscopic aspects of bronchogenic carcinoma. Otolaryngologic Clinics of North America, 6, 239.

RigleR, L.G. (1966) The earliest roentgenographic signs of carcinoma of the lung. Journal of the American Medical Association, 195, 655.

Rimington, J. (1971) Smoking, sputum and lung cancerBritish Medical Journal, 2, 373.
Rinker, C.T., Garrotto, L.J., Lee, K.R. \& Templeton, $\frac{\mathfrak{\mathbb { Q }}}{\mathfrak{d}}$ A.W. (1968) Bronchography: diagnostic signs and accur- $\varrho$ acy in pulmonary carcinoma. American Journal of Roent.genology, 104, 802.

Rome, D.S. \& Olson, K.B. (1961) Sputum specimens versus bronchial aspirates in diagnosis of bronchogenic cancer. Acta Cytologica, 5, 173.

Royal College of Physicians (1962) Smoking and Health. Summary of a report on smoking in relation to cancer of the lung and other disease. Pitman Medical, London.

Royal College of Physicians (1971) Smoking and Health Now. A new report and summary on smoking and its $\infty$ effects on health. Pitman Medical, London.

RuBin, P. (1966) Discovering the preclinical and precancerous state. Journal of the American Medical Association, 195, 662.

Russell, W.O. \& Chang, S.C. (1967) A new technique for detecting malignant cells in sputum. Cancer, 20, 681 .

Russell, W.O., Neidhart, H.W., Mountain, C.F., Grif-3. FITH, K.M. \& ChANG, J.P. (1963) Cytodiagnosis of lung cancer: A report of a five-year laboratory, clinical, and $\infty$ statistical study with a review of the literature on lung of cancer and pulmonary cytology. Acta Cytologica, 7, 1.

RYAN, R.F., MCDONALD, J.R. \& GlaGETT, O.T. (1959) In-situ carcinoma of the bronchus. Journal of Thoracic 음 Surgery, 35, 264.

Sabour, M.S., Osman, L.M., Le Golvan, P.C. \& IshaK, $\overrightarrow{-}$ K.G. (1960) Needle biopsy of the lung. Lancet, ii, 182.

Sanderson, D.R., Wang, J.K., Dawson, B. \& Fowler, W.J. (1970) Differential lung function measured at diagnostic bronchoscopy. Annals of Otolaryngology, 79, 953.₹

SANTI, L. \& CARLI, C. (1970) Cytodiagnosis on sputa from $\vec{\theta}$ asymptomatic and lung-disease affected men. Acta Cyt logica, 14, 121.

ScoTT, J.K. (1965) The diagnosis of lung cancer in com: miners. British Journal of Diseases of the Chest, 59, 13?

Selikoff, I.J., Hammond, E.C. \& Churg, J. (1968) Asbestos exposure-smoking and neoplasia. Journal of the American Medical Association, 204, 106.

Shanks, S.C. \& KerleY, P.K. (1962) A Textbook of X-ray Diagnosis, Vol. 2. Lewis, London.

Sherman, P.H., Conant, J.S. \& Peereboon, G. (1967) Car- $\overline{\bar{O}}$ cinoma of the lung: A tuberculosis hospital population. American Review of Respiratory Diseases, 96, 451.

Simons, G. (1971) Diagnostic radiology in localization of lung cancer. In: Modern Radiotherapy-Carcinoma of the Bronchus (Ed. by T. J. Deeley). Butterworths, London.

SMITH, W.G. (1965) Needle biopsy of the lung. Thorax, 1968.3 SPratT, J.S., Ter-Pogossian, M. \& Long, R.T.L. (1963) The detection and growth of intrathoracic neoplasms. Archives of Surgery, 86, 283.

SteEle, J.D. \& MARABle, S.A. (1959) Cervical mediastinotomy for biopsy. Journal of Thoracic Surgery, 37, 621.

Steel, S.J. \& Winstanley, D.P. (1967) Trephine biopsy for 0 diffuse lung lesions. British Medical Journal, 2, 30.

STEEL, S.J. (1971) The value of drill and aspiration biopsy. In: Modern Radiotherapy-Carcinoma of the Bronchus (Ed. 을 by T. J. Deeley). Butterworths, London.

STERN, H.S., Goodwin, D.A., WAGNER, Jr, H.N. \& KRAMER, 命 H.H. (1966) In ${ }^{113} \mathrm{~m}$ a short-lived isotope for lung scanning. N Nucleonics, 24, 57.

STOKES, W. (1882) A treatise on the diagnosis and treatment of $\mathrm{N}$ diseases of the chest, Part I. The New Sydenham Society.

Stradling, P. (1968) Diagnostic Bronchoscopy. Livingstone, Edinburgh and London.

STRADLING, P. (1971) Bronchoscopic examination. In: $\mathbb{Q}$ Modern Radiotherapy-Carcinoma of the Bronchus (Ed. by $\stackrel{?}{?}$ T. J. Deeley). Butterworths, London.

TaKahashi, M., HaShimoto, K. \& OSADA, H. (1967) Parenteral administration of chymotrypsin for the early $\mathbb{D}$ detection of cancer cells in sputum. Acta Cytologica, 11, 61. 
Templeton, A.W., Jansen, C., Lehr, J.L. \& Hufft, R. (1967) Solitary pulmonary lesions; computer-aided differential diagnosis and evaluation of mathematical models. Radiology, 89, 605.

Thompson, D.T. (1967) Conservative resection for bronchogenic carcinoma. Journal of Thoracic and Cardiovascular Surgery, 53, 159.

Tsubio, E., IKeda, S., Tajima, M., Shimosato, Y. \& IshiKAWA, S. (1967) Transbronchial biopsy smear for diagnosis of peripheral pulmonary carcinoma. Cancer, 20, 687.

UMIKER, W.O. (1961) The current role of exfoliative cytopathology in the routine diagnosis of bronchogenic carcinoma: A five-year study of 152 consecutive, unselected cases. Diseases of the Chest, 40, 154.

UMIKER, W.O. (1971) Reliability of cytological diagnosis. In: Modern Radiotherapy-Carcinoma of the Bronchus (Ed. by T. J. Deeley). Butterworths, London.

Umiker, W.O., Korst, D.R., Cole, R.P. \& Manikas, S.G. (1960) Collection of sputum for cytologic examination: spontaneous vs artificially produced sputum. New England Journal of Medicine, 262, 565.

UMiker, W.O., Young, L. \& Waite, B. (1958) The use of Chymotrypsin for the concentration of sputum in the cytologic diagnosis of lung cancer. University of Michigan Medical Bulletin, 24, 265.

United States Department of Health, Education and Welfare (1964) Report of the Advisory Committee to the Surgeon General of the Public Health Service, Washington, D.C.

-Public Health Service Review (1967) Washington, D.C.

-Supplement to the 1967 Public Health Service Review (1968) Washington, D.C.
Virtama, P. (1962) Mass miniature radiography of the Finnish State Railways. Annales Medicinae Internae Fenniae, 51, Suppl. 37.

WAGNER, J.C. (1971) Asbestos and cancer. In: Modern Radiotherapy-Carcinoma of the Bronchus (Ed. by T. J. Deeley). Butterworths, London.

WALSKE, B.R. (1966) The solitary pulmonary nodule. Diseases of the Chest, 49, 302.

Webber, M.M., Bennett, L.R. \& Suprenet, E.L. (1966) The technique and interpretation of lung scans using technetium-99m labelled macro-aggregated albumin. Journal of Nuclear Medicine, 7, 353.

Weiss, W., Boucot, K.R. \& Cooper, D.A. (1966a). Growthrate in detection and prognosis of bronchogenic carcinoma. Journal of the American Medical Association, 198, 1246.

Weiss, W., Boucot, K.R. \& CoOPer, D.A. (1966b) The survival of man with measurable proved lung cancer in relation to growth-rate. American Journal of Roentgenology, 98, 404.

Wilt, K.E., Andrews, N.C., Meckstroth, C.V., Molnar, W. \& KLASSEN, K.P. (1959) The role of bronchography in the diagnosis of bronchogenic carcinoma. Diseases of the Chest, 35, 517.

Woolner, L.B., Anderson, H.A. \& Bernatz, P.E. (1960) 'Occult' carcinoma of the bronchus, a study of 15 cases of in-situ or early invasive bronchogenic carcinoma. Diseases of the Chest, 37, 278.

Yano, Y., McRaE, J., Honbo, D.S. \& ANGer, H.O. (1969) $99 \mathrm{~m}$ Tc-ferric hydroxide macroaggregates for pulmonary scintiphotography. Journal of Nuclear Medicine, 10, 683.

Zajaczkowska, J., Krakowka, P. \& Kozakow, H. (1968) The role of bronchoscopy in the diagnosis of bronchial carcinoma. Polish Medical Journal, 7, 928. 